\title{
PRACTICAL ASPECTS REGARDING MAGNETIC RETAINED OVERDENTURE
}

\author{
RADU CĂTĂLIN COSTEA ${ }^{1}$, VIOREL ȘTEFAN PERIEANU ${ }^{2}$, CLAUDIA-CAMELIA BURCEA ${ }^{3}$, \\ MIHAI BURLIBAȘA ${ }^{4}$, MIHAELA CHIRILĂ ${ }^{5}$, NARCIS MARCOV ${ }^{6}$, GABRIELA TĂNASE $^{7}$, \\ NICOLETA MĂRU ${ }^{8}$, ALEXANDRU TITUS FARCAȘIU ${ }^{9}$, ȘTEFAN MILICESCU ${ }^{10}$, MĂDĂLINA \\ VIOLETA PERIEANU ${ }^{11}$, MIHAI DAVID ${ }^{12}$, CAMELIA IONESCU ${ }^{13}$, \\ ELENA-CRISTINA MARCOV ${ }^{14}$, LILIANA MORARU $^{15}$ \\ 1,2,3,4,5,6,7,8,9,10,11 ,12,13,14 “Carol Davila” University of Medicine and Pharmacy, Bucharest, \\ 15 "Titu Maiorescu" University of Medicine and Pharmacy, Bucharest
}

Keywords: overdenture, Abstract: Overdenture is a type of treatment suitable for subtotal and complete edentulous patients edentulous patient, and is characterized by making a total prosthesis, with the mucosal face embedding remaining teeth magnet keeper (remaining roots) or dental implants. In this material we will try to present some practical aspects, regarding retained overdenture with magnetic systems fixed in the remaining roots at the level of the dental arches.

\section{INTRODUCTION}

Overdenture is a type of treatment suitable for subtotal and complete edentulous patients, and is characterized by making a total prosthesis, with the mucosal face embedding remaining teeth (remaining roots) or dental implants.(1-3)

The remaining teeth (or dental implants) are used either connected with special systems or isolated, giving the prosthetic restoration a superior stability and maintenance, compared to a classic complete denture.(1-3)

The concepts of overdenture were underlined in 1970, at a session of the American Dental Association by Charles Bolender. Since then, a lot of studies have been done, which have led to several conclusions about the benefits of overdentures.(1-7)

\section{AIM}

The preservation of the remaining roots and, of course, of the alveolar bone with the help of overdentures, has been of concern to specialists for a long time, as it results from the specialized literature. Due to the overdentures, the occlusal forces transmitted evenly over the entire surface of support area reduce the resorption phenomenon.(1-3,8-11)

The use of magnetic systems, especially when mechanical systems have been contraindicated due to a deficient prosthetic support (extensive coronary damage, few remaining teeth, low VDO etc.) gives magnets an important place in dental practice.

Overdentures maintained with magnetic systems reach a high level of satisfaction among patients who have benefited from this method of prosthetic restoration. This kind of overdentures have better retention, stability and increased comfort compared to classic complete dentures.

The magnetic systems used to retain dentures are usually smaller than mechanical attachments, which are especially useful for patients with limited inter-occlusal space and high aesthetic requirements.
Magnetic systems also resolve a moderate divergence of alignment between two or more abutments, as they do not depend on a particular insertion path. In this aspect, magnetic systems differ from most mechanical systems, which generally require minimal divergence for best performance. Moreover, patients with physical disabilities reported that magnet-retained dentures are relatively easy to place and remove from the oral cavity.

In this material we will try to present some practical aspects, regarding retained overdentures with magnetic systems fixed in the remaining roots at the level of the dental arches.

\section{MATERIALS AND METHODS}

Magnetic systems can be used to maintain and stabilize both partial dentures (skeletal and / or acrylic) and complete dentures. Specifically, starting from the details mentioned above, it is necessary to specify some very important aspects that intervene in the technology of making retained prostheses with magnetic systems fixed in the remaining roots at the level of the dental arches, as follows:(1-15)

In general, a maximum of 4 magnets are used for a denture (we are talking about a bilateral distribution of teeth, preferably canines and / or premolars).

The remaining teeth must be clinically healthy (both endodontically and periodontally).

The magnet is fixed in the mucosal surface of the overdentures, and on the tooth chosen as support is fixed a small metal disk called keeper, made of a magnetizable alloy.

It is mandatory that the two parts of the system overlap perfectly, in order to obtain the corresponding magnetic attraction.

The root of the tooth used for support must have a proper root canal treatment and a correct root canal filling;

The coronary abutment, in most situations, can be of low height and the keeper will be fixed by overcasting by

\footnotetext{
${ }^{12}$ Corresponding author: Mihai David, Str. Plevnei, Nr. 19, Sector 1, București, România, E-mail: mburlibasa@ gmail.com, Phone: +40723 472632
} Article received on 30.04.2021 and accepted for publication on 04.06.2021 


\section{CLINICAL ASPECTS}

means of a metallic cast post and core, in order to avoid decimation.

- The root surface of the support tooth must not be smaller than the surface of the magnet used.

- The model of the cast post and core will be made on the master cast and will incorporate the prefabricated keeper.

- The alloy used to make the cast post and core must have a melting point below the melting point of the alloy from which the keeper supplied by the manufacturer is made.

The cast post and core that incorporates the keeper must have perfectly smooth and horizontal surface, to obtain optimal contact with the magnet.

- $\quad$ After the test and the adaptation of the cast post and core (with the keeper incorporated in it) in the oral cavity, it is cemented on the dental root, after which the overdenture is made, using classic procedures.

- After the overdenture is worn for a period of time by the patient for accommodation, on the mucosal face, right next to the keeper, the space for the magnet is created. The magnet must easily enter the newly created space, because when the patient closes in a centric relationship, the prosthetic restorations must have on the prosthetic field a position identical to the one prior to the insertion of the magnet in the newly created spaces.

- The magnets will be fixed with self-curing acrylate either in the dental office or in the dental laboratory. After obtaining the correct position of the magnet, a hole is created to eliminate the excess of the self-curing acrylate.

Next, we will present the practical implications of the technology of making 2 dentures retained with magnetic systems fixed in the remaining roots from the dental arches. The magnetic systems used in this study were those belonging to the Aichi Steel Company, namely Magfit systems.

\section{RESULTS AND DISCUSSIONS}

Clinical case No. 1

1. Patient X.S., male, aged 56, with a partially edentulous maxillary and mandible, presented to the dental office with difficulties in speech and mastication. The patient wanted maxillary and mandibular rehabilitation.

The dentist established the following treatment plan, in order to restore the functions of the dento-maxillary system:

Maxillary: it was decided to save the roots of teeth 1.1,2.1, 2.2, 2.3 and to perform a maxillary overdenture retained with magnetic systems fixed in these roots. Tooth 2.5 will be devitalized and prepared, and then will be covered with a metal cap, which will be covered by overdenture;

Mandibular: it was decided that oral rehabilitation should be made with a fixed metal-ceramic prosthesis on remaining teeth, on which a stud-attachment denture will be anchored.

Figure no. 1. Maxillary master cast

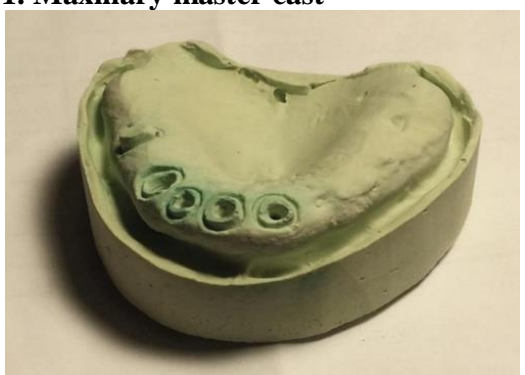

Four 800-gram force Magfit DX magnetic systems from AICH EUROPE Gmbh were used. These were incorporated in the models of cast post and core made on the master model.
Figure no. 2. Wax patterns of cast post and core attached to crucible former with sprues, before investing

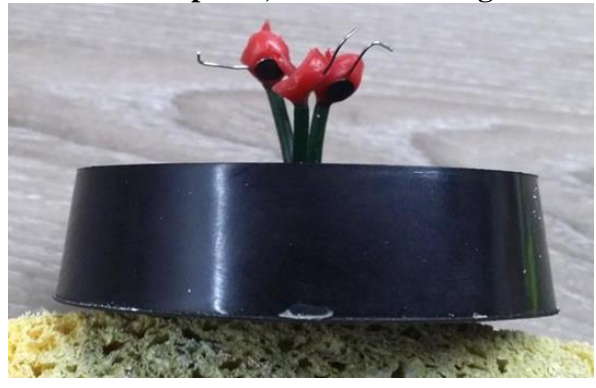

Figure no. 3. Cast post and cores after deflasking and sandblasting

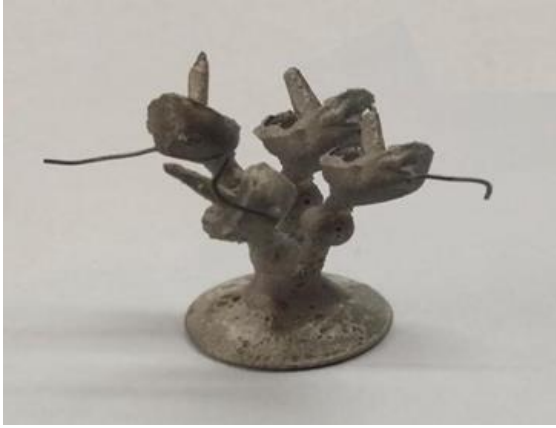

After the metal sprues were cut, the cast post and core and metal cover were adapted to the master cast, processed and polished.

Figure no. 4. The cast post and cores and metal cap adapted to the master cast.

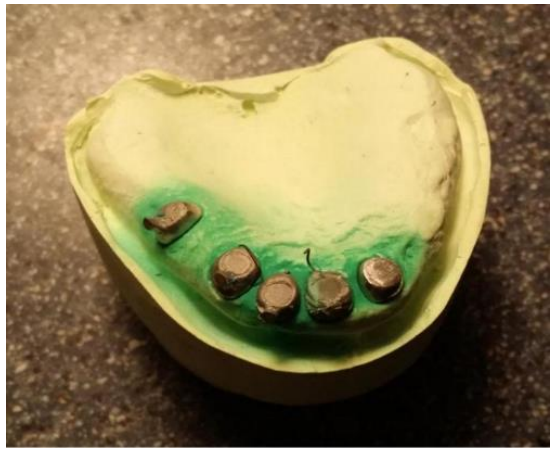

Figure no. 5. The cast post and core and the metal cap processed and polished

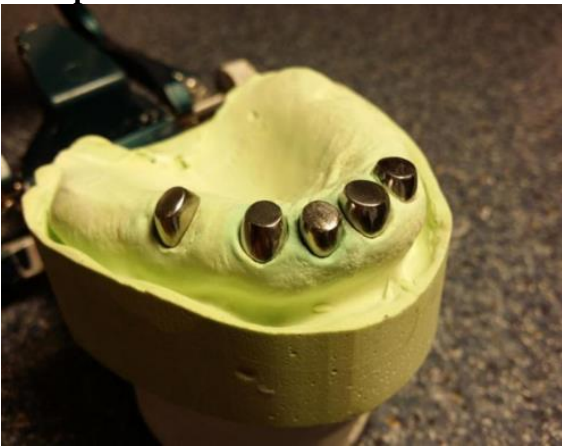

Also, at this stage, the wax pattern of the metal cap for the abutment of tooth 2.5 was made. The wax pattern of cast post and core were attached with sprues to the crucible former cover. The wax pattern was invested with specific investment materials and then cast. After cooling they were deflasked, sandblasted and processed. 


\section{CLINICAL ASPECTS}

Figure no. 6. The cast post and cores and metal cap cemented

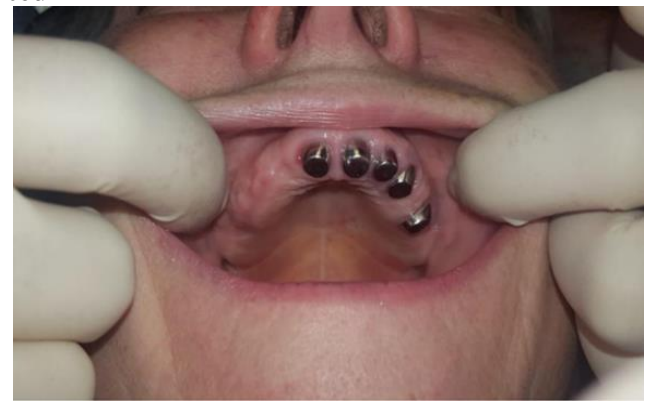

Figure no. 7. Maxillary and mandibular prosthetic restorations on the master cast, after processing and polishing

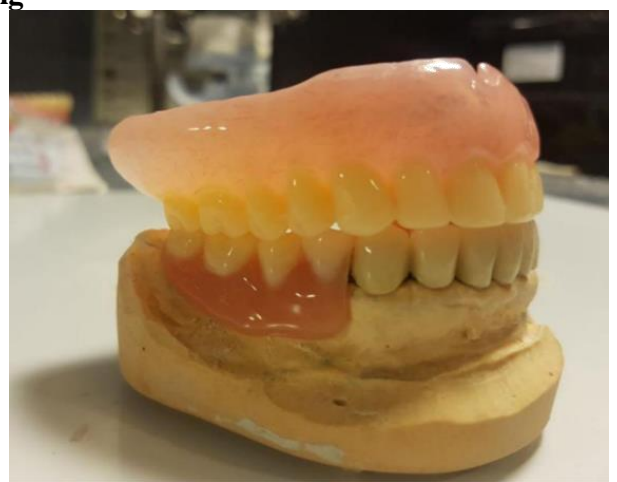

Figure no. 8. Mandibular prosthetic restorations

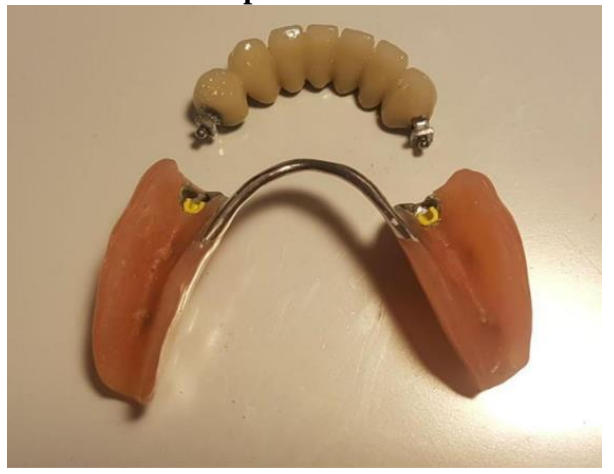

Figure no. 9. Complete maxillary overdenture processed and polished

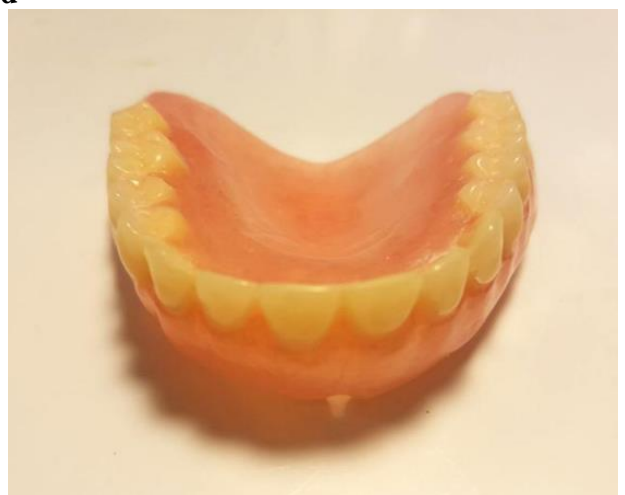

The patient wore the dentures for accommodation for a short period of time, and then, in a subsequent visit to the dentist's office, the magnets were permanently mounted in the mucosal surface of the denture, using self-curing acrylate for gluing them.
Figure no. 10. Magnets glued in the mucosal cavities of the overdenture with self-curing acrylate

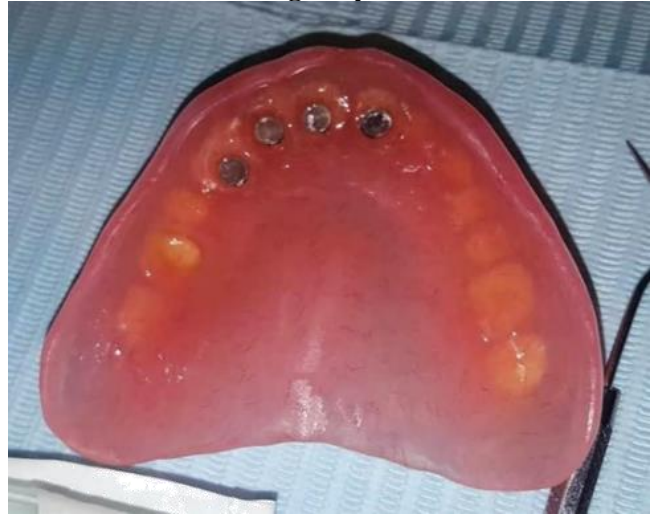

\section{Clinical case No. 2.}

2. Patient Z.L., 62 years old, male, with a partially edentulous mandible presented to the dentist's office for prosthetic rehabilitation. There were three remaining roots in the mandible, 3.5, 3.3, 4.3 and molar 3.8, which had a class III mobility. The patient was offered as a method of treatment, a mandibular overdenture on three magnets, after extraction of 3.8 .

Figure no. 11. Mandibular master cast

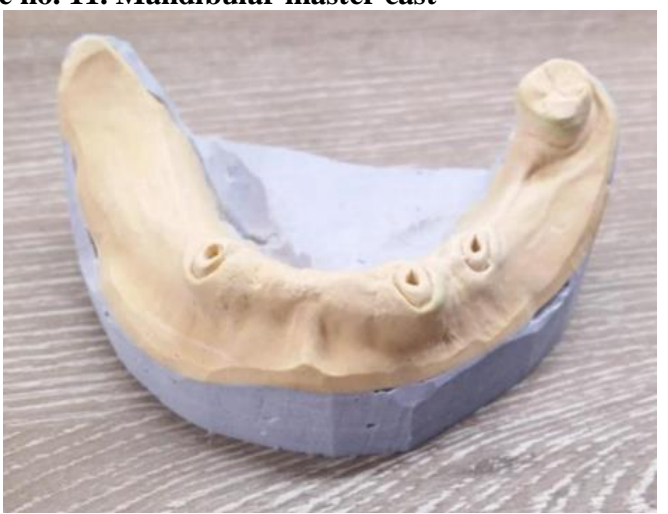

To solve this case, 3 800-gram force Magfit DX magnetic systems from AICH EUROPE Gmbh were used. These have been incorporated into the wax pattern of cast post and core made on the master cast.

Figure no. 12. The magnetic system. Magnet and keeper

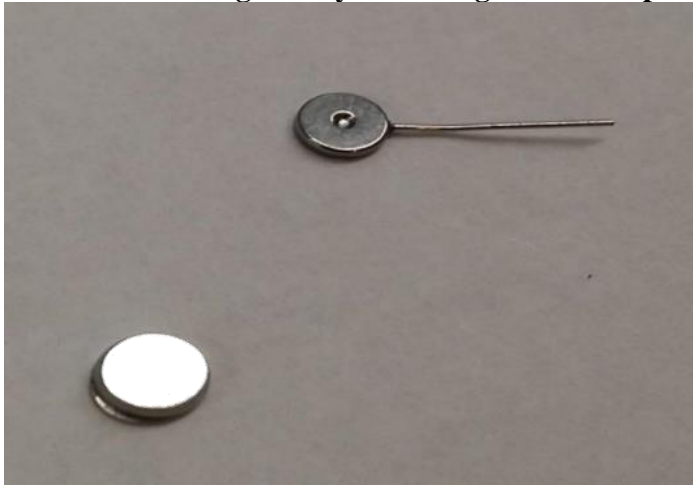

The wax pattern of post and core were attached to the crucible former with wax sprues. Then, the wax patterns were invested in specific investment materials and the metal was cast. After cooling, the cast post and cores were unpacked and processed. 
CLINICAL ASPECTS

Figure no. 13. Wax pattern of cast post and core attached with sprues to crucible former

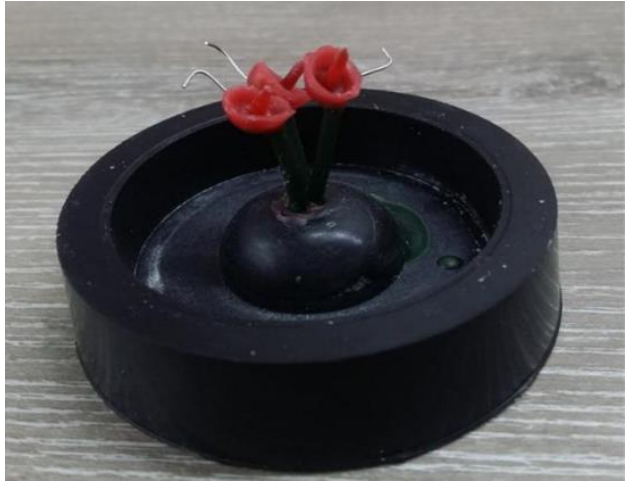

Figure no. 14. Cast post and cores after deflasking and sandblasting. Next, the metal sprues are cutted and final products processed

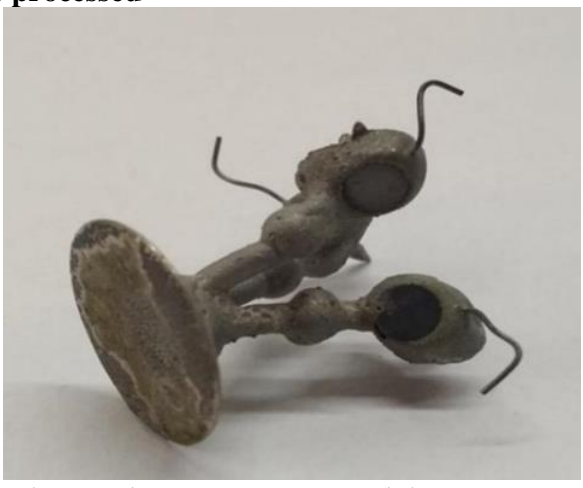

The metal sprues were cut and the cast post and cores were adapted on the master cast, processed and polished.

Figure no. 15. The cast post and cores adapted on the master cast

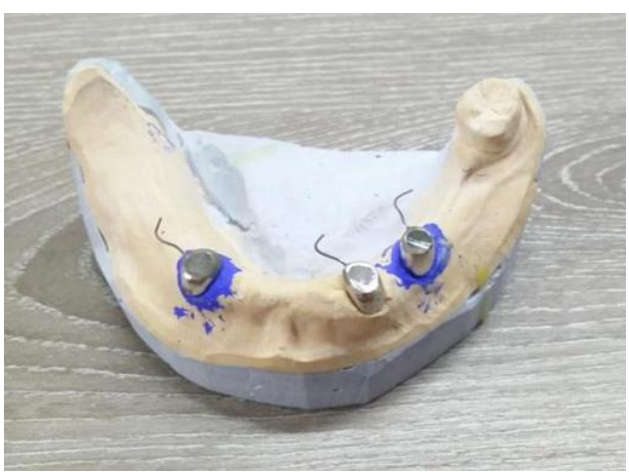

Figure no. 16. The cast post and cores processed and polished

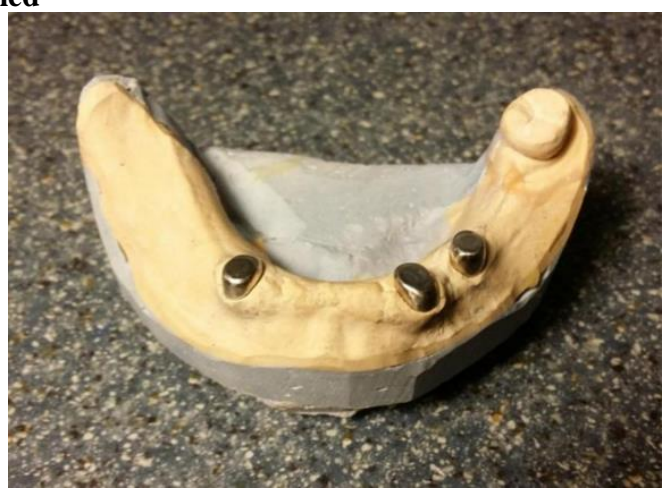

Figure no. 17. The cast post and cores cemented on teeth

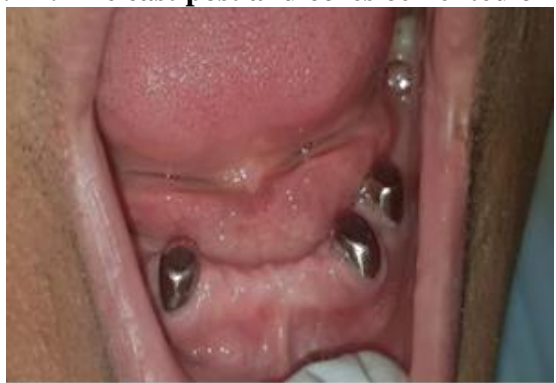

Figure no. 18. Mandibular acrylic denture processed and polished

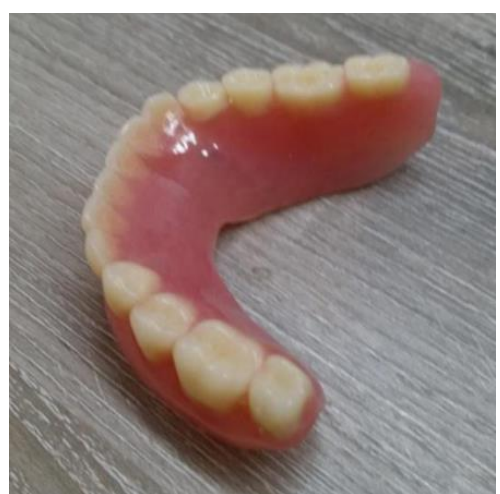

The patient wore the dentures for accommodation for a short period of time. In a subsequent visit made to the dentist's office, the magnets were permanently mounted in the mucosal area of the denture.

Figure no. 19. Mandibular overdenture with magnets mounted on the mucosal surface, in occlusion.

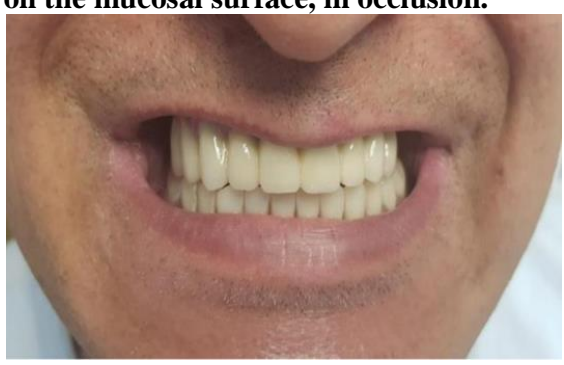

\section{CONCLUSIONS}

The use of magnetic systems on the remaining roots is an alternative for the extraction of the last teeth and the middle way between the implant supported overdentures and the classic acrylic dentures.

Magnetic systems can be used on the remaining roots (even on a single root), but also in combination with various special systems.

Magnetic systems can also be used on roots with reduced implantation that do not allow the use of another system, if there is no periodontal or apical pathology that requires tooth extraction.

The magnetic system does not malfunction, does not need to be activated or repaired. The magnetic intensity does not decrease significantly for 10 years.

Magnets can cause image distortion when investigated by MRI (Magnetic Resonance Imaging) in the head and neck area.

\section{Acknowledgement:}

In this article, all the authors have equal contribution with the first author. 


\section{REFERENCES}

1. Gligor MR, Buzatu M, Perieanu VS, Burlibașa M, Perieanu MV. Aspecte teoretice și practice în tehnologia de realizare protezei cu magneți - Parte I. În: Tendințe moderne în științele biomedicale, Vol. XII, coordonatori: Burcea C.C., Neagoe I.C., Dina M.D., Perieanu V.S., Perieanu M.V., Editura Matrivx Rom, București; 2019. p. 255-324.

2. Bratu D, Ieremia L, Uram-Țuculescu S. Bazele clinice și tehnice ale protezării edentaţiei totale. Ed. Imprimeriei de Vest, Oradea: 2003.

3. Ene L, Popovici C. Edentaţia totală. Clinică şi tratament. Curs I.M.F. Bucureşti; 1982.

4. Mocuța D, Popovici IA, Burlibasa L, Cristache G, Sfeatcu $\mathrm{R}$, Bodnar T. Impact of the living conditions on population health. Metalurgia International. 2009;14:17-19.

5. Burlibasa L, Chifiriuc MC, Lungu MV, Lungulescu EM, Mitrea S, Sbarcea G, Popa M, Marutescu L, Constantin N, Bleotu C, Hermenean A. Sythesis, physico-chemical characterization, antimicrobial activity and toxicological featurs of $\mathrm{Ag}-\mathrm{ZnO}$ nanoparticles, Arabian Journal of Chemistry. 2020;13(1):4180-4197.

6. Burlibașa M, Cernușcă-Mițariu M, Cernușcă-Mițariu S, Mițariu M, Malița M. Theoretical and practical aspects related to biomaterials decontamination in dental medicine (with reference to dental prosthetics). Metalurgia International. 2013; Vol. XVIII, No. 4, p. 261-267.

7. Mocuta D, Popovici LR, Dumitriu AS, Burlibașa L, Ionescu CA, Sfeatcu R. Life quality-condition of social welfare. Metalurgia International. 2009;14:62-64.

8. Burlibașa M, Muntianu L, Tănase G, Bucur MB, Comes $\mathrm{CA}$, Ionescu CA. Study on microbial contamination of biomaterials in medical practice. Metalurgia International. 2010; Vol. XV, Spec. Issue No. 2, p. 163-166.

9. Ispas DC, Eftene OA, Burlibașa M, Bucur MB, Tănase G, Cristache CM. Implications of titanium in orthodontics and dental facial orthopedics. Metalurgia International. 2011; Vol. XVI, Isuue No. 10, p. 72-74.

10. Tănase G, Burlibaşa M, Muntianu L, Simion I, Bucur MB, Ionescu CA. Testing the antibacterial potential of biomaterials in medical practice. Metalurgia International. 2010; Vol. XV, Spec. Issue No. 2, p. 160-162.

11. Burlibaşa M, Tănase $G$, Muntianu L, Murgu AI, Teodorescu E, Malița C. Quality of life, a multidisciplinary concept with economic and social impacts in medical practice. Metalurgia International. 2010; Vol. XV, Spec. Issue No. 4, p. 88-90.

12. Burlibașa M, Cernușcă-Mițariu M, Burcea CC, Mițariu M, Ferechide D. Halogen compounds - theoretical, physiological and practical aspects regarding the decontamination, disinfection and sterilisation of intsruments and biomaterials in dental medicine practice. Metalurgia International. 2012; Vol. XVIII, Spec. Issue No. 3, p. 54-57.

13. Eșian D, Man A, Burlibaşa L, Burlibașa M, Perieanu MV, Bică C. Salivary level of Streptococcus mutans and Lactobacillus spp. related to a high risk of caries disease. Rom Biotechnol Lett.2017;22(2):12496-12503. 